\title{
Rastro y rostros, política y estética en El botón de nácar de Patricio Guzmán
}

Trace and Faces, Politics and Aesthetics in Patricio Guzmán's El botón de nácar

\section{LAURA POMERANTZ}

\begin{abstract}
RESUMEN: Patricio Guzmán aborda una temática sustancial en su largometraje El botón de nácar (2015): la intolerancia, en dos momentos rezagados de la historia de Chile, el de los pueblos originarios y el de la dictadura militar. Trae a la superficie visual una variedad de dispositivos tales como indicios corporales, residuos identificatorios, traslados geográfico-ubicacionales, testimonios varios, emitiendo en conjunto un compromiso por recuperar verdades trágicas y ocultas. Al ver El botón de nácar, el público ingresa a un ámbito impregnado de huellas residuales, rastros de cuerpos inertes y restos mortales movidos en aquel vaivén oceánico testigo de los acontecimientos. Su lucha, pues, no se adscribe solamente a los límites del olvido, sino también a todos aquellos que lo impulsan guiados por motivos miserables. Nuestro acercamiento se enfoca básicamente en la tribu selknam, nómada pedestre de cazadores-recolectores y su visión estética detrás de la pintura corporal que desarrollaron.
\end{abstract}

ABSTRACT: Patricio Guzmán tackles a substantial theme in his feature film El botón de nácar (2015): intolerance, in two laggard moments of the history of Chile: that of the indigenous peoples and that of the military dictatorship. It brings to the visual surface a variety of devices such as physical indications, identifying residues, geographic-locational transfers and various testimonies that all together emit a commitment to recover tragic and hidden truths. Watching El botón de nácar the audience enters an area impregnated with residual vestiges, traces of inert bodies and mortal remains moved by the oceanic sway that witnesses the events. Their struggle, therefore, is not only ascribed to the limits of oblivion, but also to all those who motivate it guided by miserable reasons. Our approach focuses primarily on the Selknam tribe, pedestrian huntergatherer nomads, and on their aesthetic vision behind the body painting they develop.

PALABRAS ClAVE: Patricio Guzmán, estética selknam, exterminio.

KEYWORDS: Patricio Guzmán, Selknam aesthetics, extermination.

RECIBIDO: 20 de diciembre de 2016 • ACEPTADO: 4 de abril de 2017 
LAURA POMERANTZ

\section{Rastro y rostros, política y estética en El botón de nácar de Patricio Guzmán}

Agua, memoria y voz, estética lineal y pictórica

En un universo fragmentado como el que percibimos a diario, todo se sucede vertiginosamente. Al mismo tiempo aquella percepción nos abraza y convoca a nuestro deseo a totalizar lo que parece suelto y desensamblado. En el espíritu del tiempo en el que transitamos, donde la unidad se manifiesta de plurales maneras, Patricio Guzmán aborda una temática sustancial en su largometraje El botón de nácar (2015): la intolerancia, tras dos momentos rezagados de la historia de Chile, el de los pueblos originarios y el de la dictadura militar.

En una estructura narrativa lineal, donde la imagen poética se distingue abstracta alejándose de la realidad tangible y el tratamiento sonoro hace eco del lenguaje, la sensibilidad se asoma en cada fotograma con gran fuerza expresiva, dando pie a registros de cine experimental fusionados con el subgénero documental de cine ensayo, tras un corte político-social que subyace los 82 minutos de película a lo largo de 4200 kilómetros de costa chilena. Varios niveles de significado conviven en esta propuesta de denuncia: la mirada cuasi hipnótica, al contemplar la bellísima y majestuosa geografía chilena, testigo vivencial de tiempos de intransigencia, masacre y dictadura. En esta geografía se conjugan dos procesos, el de la perfección natural con sus cambios intrínsecos a lo largo de los siglos, y el del artificio de "civilización" que impone la 
destrucción de su pueblo al horadar las capas geológicas, cuyas raíces fueran nutriendo el suelo de atrocidades.

De este primer cruce, recordando al teórico del arte Heinrich Wölfflin, emerge un grado estético de lo geográfico-lineal entretejido con lo sociopolítico-pictórico (Wölfflin 1952: 25-315), a partir de una perspectiva aérea de contornos perfilados y cerrados, definidos e iluminados, que lindan con lo inacabado y abierto, borroso y difuminado, sumergido en una nostalgia guzmaniana de paraíso perdido, manchado de pinceladas históricas y oscuras, donde los trazos de archipiélagos, canales y fiordos, se desvanecen en la penumbra de una nación que niega su pasado. Una suerte de pacto de silencio que sólo el mar puede atesorar en aquella profundidad espacial. En otro grado de lectura, un aura de romanticismo a lo Werner Herzog abraza la trama, con paisajes sublimes, plausibles de envolver al hombre, enfrentarlo a la titánica naturaleza y establecer el contraste de proporciones, al ubicar sus dimensiones humanas en una escala reducida y de artificio. Pensemos en Théodore Géricault y La balsa de la medusa (1819), Caspar David Friedrich y el Caminante sobre el mar de nubes (1918) o William Turner y el Barco de esclavos (1940), clásicos pintores románticos del siglo XIX, cuyas composiciones de tormentosos y contemplativos mares, inmensos bloques de hielo y montañas nevadas, confrontaban las tragedias paisajísticas con las limitaciones humanas.

En aquella consideración integral, de acercamiento estructural y estilístico de contrastes visuales, el documental revela los eventos históricos entrelazados y trae pruebas contundentes, acentuando aún más sus llagas. De tal puesta en escena nos preguntamos ¿qué móviles conducen a Patricio Guzmán a horadar las heridas punzantes y abiertas de dos momentos de violencia extrema de la historia chilena, en el año 2015? Nosotros nos enfocaremos en la primera instancia histórica, la de los pueblos originarios, puntualmente los Selknam.

\section{Impunidad de siglos}

Chile, vieja tierra de leyenda y exterminio de sus habitantes originarios, ha fascinado a viajeros, aventureros, etnógrafos, misioneros, militares 
y empresarios, quienes han dejado testimonios escritos desde el siglo XVI. Uno de los ancestros de la Patagonia chilena, la tribu de cazadores-recolectores nómada pedestre selknam, arribó a la Isla Grande de Tierra del Fuego hace unos 12000 o 10000 años, probablemente en la época de las migraciones cuando se replegó la última glaciación y el continente se encontraba unido. Habitantes de la Patagonia, al norte del Estrecho de Magallanes, de parentesco lingüístico y cultural con los tehuelches del sur, los selknam del centro y del norte, compartieron "la última tierra de la gente", Karukinka, con los hausch, yámanas y kawasqar, divididos en clanes autónomos en sus territorios o haruwen (Magrassi 2010: 19). Sumidos en el paisaje, entre la fauna de guanacos y espacios acuáticos, playas, lagunas, montañas, vientos, temperaturas inhóspitas y desolación, desarrollaron, desde sus comienzos paleolíticos, su propia cosmovisión (Chapman 2008: 105-106) y poder chamánico, música y arte. Curso que, aunque inherente, sufrió un cambio irreversible y de trágico final tras el proceso de colonización: hacia 1885 su población disminuyó y sus sobrevivientes fueron confinados a reservas promovidas por las misiones evangelizadoras de los salesianos: la de la Isla de Dawson en Chile y la de Nuestra Señora de la Candelaria, en Río Grande, Argentina.

En aquella solemnidad intrínseca, previa a la llegada del hombre blanco, según la creencia selknam, hubo un tiempo distante al tiempo humano llamado Hówenli en el que las fuerzas de la naturaleza se repartieron el origen de la existencia (Colombres 2012: 127). Esta historia atemporal, enmarcada primeramente en una era matriarcal, fue registrada por el cronista italiano Antonio Pigafetta durante la expedición de Fernando de Magallanes (1519-1521) (Montes 2013: 33). Dentro de aquel vaivén de comunión innata con la tierra, se encontraron evidencias arqueológicas de pigmentos naturales utilizados como pintura corporal (Fiore y Saletta 2012: 203-212) - cual rastro de un lenguaje que demarcara la estratificación social y los roles de los chamanes, los estados de ánimo-, así como empleados para la protección “...de la piel contra los elementos climáticos, con el objeto de embellecerse, para casarse, en situaciones de duelo y durante ceremonias de iniciación" (Fiore 2006: 13). Los colores básicos (rojo, blanco y 
negro) eran tomados de la tierra, arcilla, ceniza, carbón vegetal, yeso y limo, entre otros, para crear composiciones aparentemente sencillas de puntos, líneas, círculos, bandas y fondos de color. Uno de los momentos más frecuentes en el que pintaban sus cuerpos era el hain, rito de iniciación de los jóvenes o klóketen de entre 17 y 18 años, que al adentrarse a la madurez debían atravesar recorridos complejos en los bosques y cumplir con rigor y alta responsabilidad objetivos arduos como subir montañas, cazar guanacos, llevar cargas pesadas, entre otros. Estas dificultades impuestas por los durísimos inviernos patagónicos, se agravaban con la aparición de las deidades corporizadas en hombres, quienes espantaban a los muchachos a lo largo de la travesía hasta llegar a destino, a las chozas ceremoniales. Las máscaras y las pinturas personificaban la variedad de espíritus, "algunos insolentes y jocosos, otros muy severos y temidos, como Shoort, el espíritu de las piedras blancas, que lleva dos cuernos en la cabeza y va armado con un palo, con el que castiga al que alcanza" (Colombres 2012: 243). Por otro lado, eran acosados por Ulen, espíritu masculino del norte, “...payaso extremadamente diestro, nos dice Anne Chapman, caracterizado por una cabeza formidable y algo puntiaguda, su participación en el Hain, es más teatral que ritual, es decir, más profana que sagrada" (272).

Las composiciones de diseños equilibrados de colores y elementos geométricos distribuidos a lo largo del cuerpo, enfatizaban la materia adaptada a las formas y volúmenes del cuerpo, otorgando un alto grado de expresividad, sentido abstracto y sintético, además de un naturalismo espontáneo y creativo. Se plasmaba lo esencial y se delineaban los contornos dando como resultado un delicado sentido de la estética y claros principios compositivos, parte intrínseca del arte predominante en las culturas antiguas. Regresando al documental, Patricio Guzmán hace eco de las composiciones selknam al abstraer las gotas de agua en sus diferentes modos experimentales, cuales puntos pintados en la piel - o bien, estrellas, sinónimo de sus antepasados - reflejando la relación intrínseca hacia lo conocido, a modo de espejo, como afirmara el poeta Raúl Zurita: "en sus cuerpos se ve el cosmos entero". 


\section{Entre botón y botón, de exterminio en exterminio}

Dos botones enlazan los ámbitos temporales del documental, uno pertenece a un indígena yámana del siglo XIX y el otro a un prisionero político bajo la dictadura de Pinochet. El primero tiene nombre y apellido, el segundo es anónimo. Jemmy Button a sus catorce años adquiere una identidad impuesta por haber recibido su padre un botón de manos de un capitán británico, a cambio de la travesía obligada a tierras "civilizadas", Londres en 1830. Por su parte, el prisionero se descubre en el fondo del mar amarrado a un riel, cuyo peso corroboraría una muerte segura al ser arrojado cual objeto inanimado y, al mismo tiempo, fungiría como testimonio, ya que al adherírsele elementos identificatorios, le otorgaría credibilidad al momento de reconstruir los hechos. Ambos seres humanos, vestigios de vivencias violentadas en tiempos genocidas, adquieren la calidad de referentes de duelos sociales silenciados, al legitimar los exterminios en sus respectivos presentes así como en los entornos político-sociales de los tiempos por venir.

El yámana Orundellico (1815-1864), expuesto en la Corte Real de Saint James en 1831, envuelto luego en vestimenta europea y obligado a vivir en el exilio, regresaría a sus tierras aturdido por las violaciones de sus derechos humanos básicos. El preso sin nombre, torturado y asesinado como consecuencia de una inyección letal, habría sido “....amarrado [al riel] con alambres, [...] cubierto con bolsas de plástico, y finalmente empaquetado con sacos de arpillera para ser arrojado a las aguas del Pacífico...", como explica el periodista y escritor Javier Rebolledo en la película. Este sistema explotado bajo la dura represión militar nos conduce a otro espacio que no podía dejar de ser mencionado por Patricio Guzmán, la Isla de Dawson, donde el horror se volvería a duplicar, ya no a través de un simple botón sino de una dimensión geográfica, alejada e inhóspita. Vería, por un lado, el fin de los selknam, confinados allí por las misiones salesianas a principios del siglo XX y, por otro, adquiriría la calidad de campo de concentración para los ministros de Allende, como narra la voz en off del director, “....más de 700...[de sus] seguidores que vivían en Punta Arenas...". 
A modo de conclusión

Las sombras del ayer no nos dejan crecer y la nostalgia es un ancla fija en la eternidad, los palacios y tumbas adornan una ciudad habitada por hombres y no por los recuerdos, ecos de años dorados, espejismos del poder

bajo esa tristeza espera nuestro presente.

CHEUQuelaf (2015)

Patricio Guzmán no sólo denuncia, también invita a la reflexión sobre la violencia extrema, deliberada y silenciada, bajo un mar que fungiera aparentemente de objeto inanimado - otro más - capaz de esconder secretos, en un país que no logra asumir sus realidades ni alcanzar pauta alguna de justicia, reivindicación o reparación. ¿Cómo logra dicha reflexión? Trae a la superficie visual una variedad de dispositivos tales como indicios corporales, residuos identificatorios, traslados geográficoubicacionales, testimonios varios, emitiendo en conjunto un compromiso por recuperar verdades trágicas y ocultas, tras la urgencia imperiosa de sacudir conciencias. En su estilo documental sobrevive una narración omnipresente, donde conviven momentos de violencia histórica, y es en este cine ensayo donde logra reunir la memoria de un pueblo que aún no ha podido encontrar un balance que se incline hacia la justicia. Al ver El botón de nácar, el público ingresa a un ámbito impregnado de huellas residuales, rastros de cuerpos inertes y restos mortales movidos en aquel vaivén oceánico testigo de los acontecimientos, pruebas que ponen en tela de juicio las políticas imperantes y los respectivos discursos oficiales. Su lucha, pues, no se adscribe solamente a los límites del olvido, sino, también, sobre todos aquellos que lo impulsan guiados por motivos miserables. Recordemos que el manejo de la memoria siempre ha sido un instrumento utilizado por los sistemas de dominación, por parte de quienes pretenden determinar lo que se debe recordar y aquello que se debe olvidar. 


\section{Bibliografía}

ChAPMAn, Anne (2008). Fin de un mundo, Los selknam de Tierra del Fuego. Buenos Aires, Zagier and Urruty Publications.

CheuQuelaf, Rafael (2015). "Chile, exterminio del pueblo Selknam y su sombra en el Magallanes de hoy", <http://regeneracion.mx/selknam/>, consultado por última vez el 28 de octubre de 2016.

Colombres, Adolfo (2012). Seres mitológicos argentinos. Buenos Aires, Colihue

FIORE, Dánae (2006). "La manipulación de pinturas corporales como factor de división social en los pueblos selknam y yámana (Tierra del Fuego)", Estudios Atacameños, núm. 31: 129-142.

Fiore, Dánae y María José SALETTA (2012). "El uso de pigmentos en la ceremonia del hain selknam. Información etnográfica y evidencia arqueológica de los sitios Ewan 1 y 2 (Tierra del Fuego, Argentina)", en María Estela Mansur y Raquel Piqué Huerta (eds.), Arqueología del Hain. Investigaciones etnoarqueológicas en un sitio ceremonial de la sociedad selknam de Tierra del Fuego. Implicancias teóricas y metodológicas para los estudios arqueológicos. Madrid, Consejo Superior de Investigaciones Científicas: 203-212.

MONTES, Nahuel (coord.) (2013). Cuentos, mitos y leyendas patagónicos. Buenos Aires, Ediciones Continente.

NiCOLETTI, María Andrea (2006). "Los misioneros salesianos y la polémica sobre la extinción de los selk'nam en Tierra del Fuego”, Revista Anthropologica, año XXIV, núm. 24: 153-177.

WöLFFLIN, Enrique (1952). Conceptos fundamentales de la historia del arte. Madrid, Espasa Calpe. 